\title{
Primary Tubercular Otitis Media: A Case Report
}

\author{
Tulachan Bishow*1 and Shreshtha Krishna Bahadur² \\ ${ }^{1}$ Lecturer, Nepal \\ ${ }^{2}$ Senior Consultant, Nepal
}

Submission: November 02, 2018; Published: November 15, 2018

*Corresponding author: Bishow Tulachan, Department of ENT-HNS, Bhairahawa, Lumbini, Nepal

\section{Abstract}

Objective: To consider one of the differential diagnoses of aural polyp as tubercular otitis media and the treatment measures henceforth.

Case Presentation: A 23 year-old man presented to us with complaint of right ear discharge with fullness and not improving with the routine antimicrobial therapy. Examination showed an aural polyp filling entire EAC (external auditory canal) with foul smelling discharge, PTA (pure tone audiogram) showed profound hearing loss and sclerotic mastoid was seen in x-ray of mastoid. Radical mastoidectomy was performed and the HPE (histopathology examination) of the granulations confirmed tuberculosis.

Conclusion: Tuberculosis can be one of the causes of aural polyp despite a rare entity. However, it has a good prognosis on prompt diagnosis and treatment with surgery and the chemotherapy.

Keywords: Tubercular Otitis Media; Aural Polyp; Sclerotic Mastoid

\section{Introduction}

Tuberculosis (TB) is very common in developing countries like Nepal. It can affect any part of the human body. Most of the times, lungs are primarily affected and may manifest as extrapulmonary TB. The incidence of middle ear TB is less than $1 \%$ among the extrapulmonary TB i.e 12-15\%. Regarding the tubercular otitis media or tubercular mastoiditis, Mycobacterium tuberculosis is the principal causative agent, however, other atypical agents such as Mycobacterium bovis, Mycobacterium avium and Mycobacterium fortiutum are also responsible. Primary aural TB is very rare. Tubercular agents gain access to middle ear mainly via eustachian tube secondary to pulmonary TB consequent to the retrograde flow of hemoptysis and direct entry into the middle ear via perforated TM through EAC. Also, it may get infected from other extrapulmonary sites like pleura, lymph nodes, abdomen, genitourinary tract, skin, joints and bones or meninges. Owing to confusion with other acute or chronic middle ear problems, its diagnosis as well as the treatment gets delayed. Consequently, the delay leads to complications like facial paralysis and the irreversible hearing loss [1-7].

\section{Case Report}
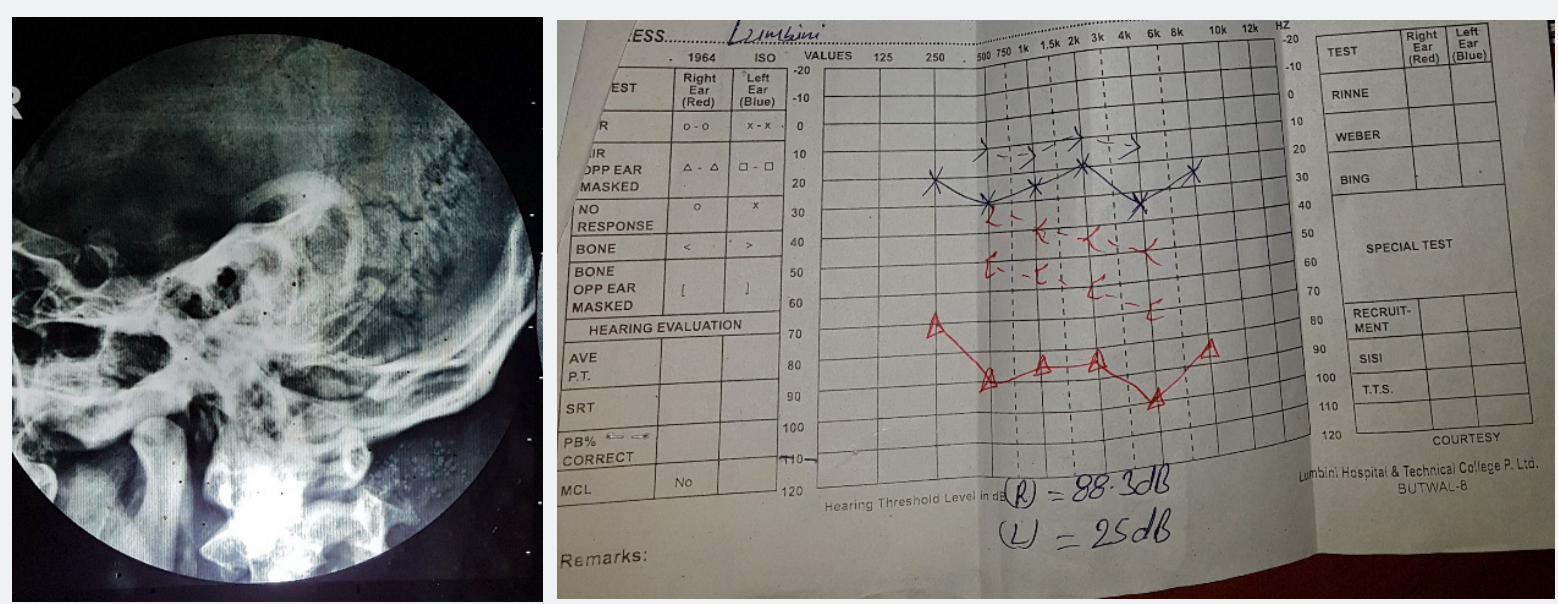

Figure 1: A) x-ray of right mastoid showing sclerosis with cavitation and B) preoperative PTA. 


\section{Global Journal of Otolaryngology}

A 23 year old man presented to ENT (ear, nose and throat) OPD (out patient department) with the complaints of right ear fullness, foul smelling discharge for 12 months. He had not improved with the several medications provided by the other health care centers. On examination, a single rounded fleshy polypoidal mass was seen covering the entire EAC with minimal foul smelling mucopurulent discharge. Patient was advised for x-ray of mastoids and pure tone audiogram. It showed sclerotic mastoid and profound hearing loss on the right side (Figures $1 \mathrm{~A} \& 1 \mathrm{~B}$ ). He underwent radical mastoidectomy under general anesthesia. Per operatively, polypoidal mass was arising from the stapes footplate, granulation tissue was present in mesotympanum, attic, aditus, antrum, periantrum, sinodural angle, stapes region, sinus tympani, eustachian tube region and anterior epitympanum along with cholesteatoma in stapes, sanist tympani, attic, aditus, antrum, periantrum and retrolabyrinthine regions. Entire ossicles were eroded. Stapes footplate was intact and mobile. Facial nerve was intact. Middle cranial and posterior cranial fossa and sigmoid sinus were intact (Figures 2A-2C). Granulation tissue were sent for histopathology and it showed stratified squamous epithelial lining and ill-defined granulomas in the stroma consisting of neutrophils, lymphocytes, necrotic foci and langheran's type of multinucleated giant cells suggestive of tubercular granulomatous lesion. Patient was started on CAT (category)-I ATT (anti tubercular therapy). On $2^{\text {nd }}$ moth follow up, he had a dry cavity.
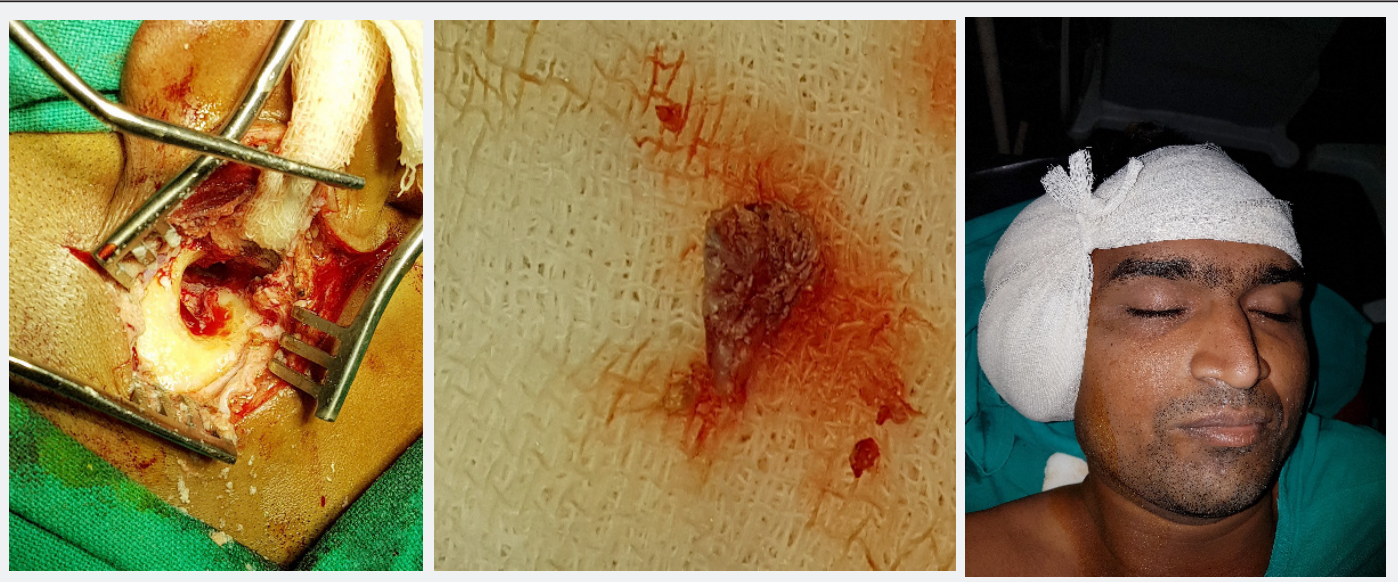

Figure 2: A) Intraoperative view of granulations mixed with cholesteatoma, B) Excised granulation tissue and C) Immediate post-operative status with mastoid pressure bandage in situ with intact facial nerve.

\section{Discussion}

In developing countries like Nepal, TB is one of the leading chronic infectious diseases affecting both the pulmonary and extrapulmonary organs $[1,8]$. In pediatric population age $>5$ years old, TB remains the leading cause of mortality throughout the world [7]. Prior to antibiotics days, CSOM (chronic suppurative otitis media) secondary to tuberculosis were seen in $2-8 \%$ of all cases and $50 \%$ of cases were in infants. There are very few TOM cases reported in the literature. The incidence of tuberculous otitis media (TOM) has declined enormously since the beginning of the last century as per Mill's study. Meantime, tubercle bacillus was reasonable for $3-5 \%$ of otitis media cases whereas it's a rare condition these days mainly due to effective childhood immunization programmes $[7,8]$. Primary TOM is extremely rare. Majority are secondary to pulmonary etiology via several mechanisms like spread through the Eustachian tube usually the result of retrograde flow of hemoptysis, direct entry via the external auditory canal or perforated tympanic membrane (TM), contiguous involvement from adjacent intracranial or extracranial infected foci, hematogenous spread and rarely via transplacental transmission or infected birth canal $[9,10]$.

Jean Louis Petit (18 $8^{\text {th }}$ century) was the first to describe about tuberculous mastoiditis and Wilde (1853) enlightened the detailed clinical insights, Koch found tuberculous bacillus in 1882 and Esche demonstrated bacillus in middle ear secretions in 1883 [7,9]. The classical characteristics of TOM initially described by Wallmer in 1953 were painless otorrhea, multiple tympanic membrane perforations, pale granulation tissue, ipsilateral facial nerve paralysis, early severe hearing loss and bone necrosis. However, it's rare to find multiple TM perforations (once considered landmark) these days as in the early stages it may coalesce into a total TM perforation accompanied by pale granulation tissue. Also, Skolnik et al study found reduced incidence of facial nerve paralysis $(16 \%$ of cases only). The hearing loss is usually on higher side than the expectation. Conductive deafness is noticeable in $90 \%$ of cases and mixed or sensorinerual type is also seen with the disease progression. Generally, TB of middle ear is unilateral however, bilateral involvement have been reported $[7,9]$. It is a challenging task to diagnose TOM as it requires a high level of suspicion and is based on pre and post-operative histological and bacteriological findings [9].

The diagnosis is made with the smear examination and culture of ear discharge or the aspirate, histopathological examination of the excised tissue and polymerase chain reaction (PCR) of the aspirate. Also, concurrent focus of TB in the other parts aids in diagnosis. Epithelioid granulomas and Langheran's giant cells in background of lymphocytes and histiocytes, and necrosis are suggestive of tuberculous etiology during histopathological examination [10]. In our case, the patient was not improving with 
the several antimicrobial therapy both oral and topical. Also, the routine hematological, chest x-ray and mantoux test were within nomal limits. However, PTA revealed profound mixed hearing loss and the x-ray of mastoid showed sclerosis with cavitation. Keeping in mind of chronic granulomatous disease, radical mastoidectomy was done under general anesthesia and the excised granulation sent for HPE confirmed TB. Surgery is done mainly for biopsy purpose in suspicious cases and in management of complications like facial palsy, postauricular fistula, subperiosteal abscess, labyrinthitis, removal of bony sequestrum and intracranial extension. Combined therapy with surgery and chemotherapy have a good chance of healing with dry ear and with better prognosis $[9,10]$.

\section{Conclusion}

TOM is a rare potentially dangerous entity if left untreated. It should be kept in differential diagnosis of prolonged discharging ear unresponsive to antimicrobial therapy. Delayed diagnosis increases chances of complications like facial nerve paralysis, labyrinthitis. Its incidence has been seen rising. Chances are higher in immune-compromised patients with diabetes mellitus etc. Timely diagnosis with initiation of ATT makes it a curable and safe disease. Surgery is usually done for confirming diagnosis and also to make ear safe.

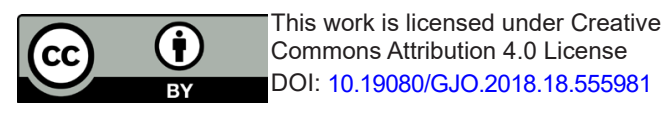

\section{References}

1. Gulati A, Kakkar V, Sharma C, Pareek M, Bishnoi S (2017) Tuberculosis of Middle Ear. Int J Adv Integ Med Sci 2(2): 104-105.

2. Saleh E, Alnemare AK, Alzuraiqi B, Abbass M (2016) Bilateral tuberculous otitis media; a rare case report. Saudi Journal of Otorhinolaryngology Head and Neck Surgery 18(1): 31-33.

3. Muhtar I, Arumugam PA, Kamalden TM (2017) Tuberculous otomastoiditis: a rare entity. Rawal Medical Journal 42(3): 440-443.

4. Araujo MF, Pinheiro TG, Raymundo IT, et al (2011) Tubercular Otitis Media. Int Adv Otol 7(3): 413-17.

5. Carvalho C, Velankar H, Pusalkar AG (2018) Tuberculous Otitis Media with Facial Paralysis -Case Report and Review of Literature. Otolaryngology Open Access J 3(2): 1-4.

6. Burse KS, Sharma S, Bharadwaj C, Kulkarni SV (2017) Primary Tuberculous Otitis Media : A Case Report. Journal of Dental and Medical Sciences 16(2): 48-51.

7. Aremu SK, Alabi BS (2010) Tuberculous otitis media: a case presentation and review of the literature. BMJ Case Reports pp. 1-4.

8. Baskota DK, Sinha BK (1998) Acute tuberculous mastoiditis. Journal of Institute of Medicine 20(3): 1-3.

9. Maheshwari A, Panigrahi R (2017) Tubercular otitis media: an under diagnosed entity. Int J Otorhinolaryngology Head Neck Surg. 3(1): 8287.

10. Adhikari P, Guragain R, Bhusal CL (2010) Tubercular Otitis Media with Facial Palsy: A Case Report. Nepalese Journal of ENT Head \& Neck Surgery 1(1): 17-18.

\section{Your next submission with Juniper Publishers will reach you the below assets}

- Quality Editorial service

- Swift Peer Review

- Reprints availability

- E-prints Service

- Manuscript Podcast for convenient understanding

- Global attainment for your research

- Manuscript accessibility in different formats

( Pdf, E-pub, Full Text, Audio)

- Unceasing customer service

Track the below URL for one-step submission https://juniperpublishers.com/online-submission.php 